\title{
Adjuvant Activity of Synthetic Lipid A of Alcaligenes, a Gut-Associated Lymphoid Tissue-Resident Commensal Bacterium, to Augment Antigen-Specific IgG and Th17 Responses in Systemic Vaccine
}

\author{
Yunru Wang ${ }^{1,2}$, Koji Hosomi ${ }^{1}$, Atsushi Shimoyama ${ }^{3}$, Ken Yoshii ${ }^{1,4}$, Haruki Yamaura ${ }^{3}$, \\ Takahiro Nagatake ${ }^{1}$, Tomomi Nishino ${ }^{1}$, Hiroshi Kiyono ${ }^{5,6,7,8}$, Koichi Fukase ${ }^{3}$ \\ and Jun Kunisawa 1,2,4,5,9,10,11,* \\ 1 Laboratory of Vaccine Materials, Center for Vaccine and Adjuvant Research, \\ and Laboratory of Gut Environmental System, National Institutes of Biomedical Innovation, \\ Health and Nutrition (NIBIOHN), Osaka 567-0085, Japan; wan@nibiohn.go.jp (Y.W.); \\ hosomi@nibiohn.go.jp (K.H.); k-yoshii@nibiohn.go.jp (K.Y.); nagatake@nibiohn.go.jp (T.N.); \\ pipipi_hiyoko2@yahoo.co.jp (T.N.) \\ 2 Graduate School of Pharmaceutical Sciences, Osaka University, Suita, Osaka 565-0871, Japan \\ 3 Department of Chemistry, Graduate School of Science, Osaka University, Osaka 560-0043, Japan; \\ ashimo@chem.sci.osaka-u.ac.jp (A.S.); yamaurah18@chem.sci.osaka-u.ac.jp (H.Y.); \\ koichi@chem.sci.osaka-u.ac.jp (K.F.) \\ 4 Graduate School of Medicine, Osaka University, Osaka 565-0871, Japan \\ 5 International Research and Development Center for Mucosal Vaccines, The Institute of Medical Science, \\ The University of Tokyo, Tokyo 108-8639, Japan; kiyono@ims.u-tokyo.ac.jp \\ 6 IMSUT Distinguished Professor Unit, The Institute of Medical Science, The University of Tokyo, \\ Tokyo 108-8639, Japan \\ 7 Graduate School of Medicine, Chiba University, Chiba 260-8670, Japan \\ 8 Department of Medicine, School of Medicine and CU-UCSD Center for Mucosal Immunology, \\ Allergy and Vaccine, University of California, Oakland, CA 92093-0063, USA \\ 9 Graduate School of Dentistry, Osaka University, Osaka 565-0871, Japan \\ 10 Department of Microbiology and Immunology, Graduate School of Medicine, Kobe University, \\ Hyogo 650-0017, Japan \\ 11 Research Organization for Nano \& Life Innovation, Waseda University, Tokyo 162-0041, Japan \\ * Correspondence: kunisawa@nibiohn.go.jp; Tel.: +81-72-641-9871; Fax: +81-72-641-9872
}

Received: 17 June 2020; Accepted: 15 July 2020; Published: 20 July 2020

\begin{abstract}
Alcaligenes spp. are identified as commensal bacteria and have been found to inhabit Peyer's patches in the gut. We previously reported that Alcaligenes-derived lipopolysaccharides (LPS) exerted adjuvant activity in systemic vaccination, without excessive inflammation. Lipid A is one of the components responsible for the biological effect of LPS and has previously been applied as an adjuvant. Here, we examined the adjuvant activity and safety of chemically synthesized Alcaligenes lipid A. We found that levels of OVA-specific serum IgG antibodies increased in mice that were subcutaneously immunized with ovalbumin (OVA) plus Alcaligenes lipid A relative to those that were immunized with OVA alone. In addition, Alcaligenes lipid A promoted antigen-specific $\mathrm{T}$ helper 17 (Th17) responses in the spleen; upregulated the expression of MHC class II, CD40, CD80, and CD86 on bone marrow-derived dendritic cells (BMDCs); enhanced the production of Th17-inducing cytokines IL-6 and IL-23 from BMDCs. Stimulation with Alcaligenes lipid A also induced the production of IL- 6 and IL-1 $\beta$ in human peripheral blood mononuclear cells. Moreover, Alcaligenes lipid A caused minor side effects, such as lymphopenia and thrombocytopenia. These findings suggest that Alcaligenes lipid A is a safe and effective Th17-type adjuvant by directly stimulating dendritic cells in systemic vaccination.
\end{abstract}


Keywords: Alcaligenes faecalis; Th17; lipid A

\section{Introduction}

The gut microbiota substantially affect the host immune system, such as the development and maturation of lymphoid tissues, promotion of intestinal IgA production, and recruitment of $\mathrm{T}$ cells and dendritic cells (DCs) [1-5]. For example, germ-free mice have smaller sized Peyer's patches (PPs) and fewer IgA-producing plasma cells, $\mathrm{CD}^{+} \mathrm{T}$ cells, and DCs in the intestine $[6,7]$. Technological advances in the analysis of commensal bacteria have enabled the identification of specific functions of bacteria involved in the regulation of host immunity. For example, Bacteroides and E. coli induce the formation of isolated lymphoid follicles in the intestine [8]. Segmented filamentous bacteria induce the differentiation of T helper 17 (Th17) cells and IgA production [9], whereas Clostridium strains induce the accumulation of regulatory $\mathrm{T}$ cells in the intestine [10].

Although many studies have focused on commensal bacteria that inhabit the intestinal lumen or epithelium, we previously reported that commensal bacteria are also resident inside gut-associated lymphoid tissue (GALT), such as PPs [11]. The predominant resident symbiotic bacteria in PPs are Alcaligenes spp., which are Gram-negative facultatively anaerobic bacteria and belonged to the class of the Gram-negative Betaproteobacteria. Our previous study revealed that Alcaligenes spp. That enter the PPs via microfold cells (M cells) are then captured by DCs and induce the production of IL-6 and IL-10, leading to the subsequent secretion of IgA in the intestine [12].

Bacterial components, such as polysaccharide and lipopolysaccharide (LPS), are well known to show activating effects on host immune responses [13,14]; therefore, they have been considered as vaccine adjuvants $[15,16]$. Adjuvants enhance the efficacy of vaccines, which can reduce the amount of antigen required, thereby lowering cost and improving efficacy in populations of poor responders, such as neonates, immunocompromised individuals, and the elderly [17,18]. In this regard, our previous study showed that Alcaligenes-derived LPS is a weak agonist for toll-like receptor 4 (TLR4), promoting the production of IgA-enhancing cytokines, such as IL-6, from DCs [19]. When used as an adjuvant, Alcaligenes-derived LPS consistently enhances antigen-specific immune responses, including antibody production and Th17 response, without excessive inflammation [19]. LPS consists of a core, an O-antigen, and lipid A [20]. The chemical structure of lipid A varies among bacteria and shows different biological activities [20,21]. Based on our previous findings on the adjuvant activity of Alcaligenes LPS, we aimed to examine the efficacy and safety of chemically synthesized Alcaligenes lipid A when used as a vaccine adjuvant.

\section{Materials and Methods}

\subsection{Mice}

Female BALB/c mice (aged 8 weeks) were purchased from CLEA Japan, Inc. (Tokyo, Japan) and kept in a specific pathogen-free environment at the National Institutes of Biomedical Innovation, Health and Nutrition (NIBIOHN) (Osaka, Japan). All animal experiments were conducted in accordance with the Animal Care and Use Committee guidelines of the NIBIOHN (Approval Nos. DS25-2, DS25-3).

\subsection{Preparation of Lipid $A$}

Alcaligenes lipid A was chemically synthesized as previously described [22]. Alcaligenes lipid A was dissolved in dimethyl sulfoxide (DMSO) (Nacalai Tesque, Inc., Kyoto, Japan) at a concentration of $1 \mathrm{mg} / \mathrm{mL}$ for the stock. For immunization, $1 \mathrm{mg} / \mathrm{mL}$ of Alcaligenes lipid A was diluted to the concentration of $10 \mu \mathrm{g} / \mathrm{mL}$ with PBS to mix with OVA in PBS. 


\subsection{Immunization}

On days 1 and 10, mice were injected subcutaneously in the back with a total volume of $0.2 \mathrm{~mL}$ vaccine that contained with $1 \mu \mathrm{g}$ of OVA (Sigma-Aldrich, St. Louis, MO, USA) alone, $10 \mu \mathrm{g}$ of OVA alone, or $1 \mu \mathrm{g}$ of OVA plus $1 \mu \mathrm{g}$ of Alcaligenes lipid A.

\subsection{Enzyme-Linked Immunosorbent Assay}

Ninety-six-well immunoplates (Thermo Fisher Scientific, Inc., Waltham, MA, USA) were coated with $1 \mathrm{mg} / \mathrm{mL}$ OVA diluted in PBS and left overnight at $4{ }^{\circ} \mathrm{C}$. The solution in the plates was removed, and 1\% (w/v) BSA (Nacalai Tesque, Inc.), dissolved in PBS, was added to the plates and incubated at room temperature for $2 \mathrm{~h}$. Plates were washed 3 times with wash buffer $(0.05 \%$ [v/v] Tween 20 [Nacalai Tesque, Inc.] in PBS). Serum samples, diluted with 1\% (w/v) BSA and 0.05\% (v/v) Tween 20 in PBS, were plated in serial dilutions and then, incubated for $2 \mathrm{~h}$ at room temperature. Goat anti-mouse IgG, IgG1, IgG2b, and IgG3, conjugated with horseradish peroxidase (SouthernBiotech, Inc., Birmingham, AL, USA), were diluted at a dilution of 1:4000 with 1\% (w/v) BSA (Nacalai Tesque, Inc.) and $0.05 \%(v / v)$ Tween 20 in PBS, and then, incubated for $1 \mathrm{~h}$ at room temperature. Plates were washed 3 times with wash buffer. Tetramethylbenzidine peroxidase substrate (SeraCare Life Sciences, Inc., Milford, MA, USA) was added to the plates and then, incubated for 2 min at room temperature. Next, $0.5 \mathrm{~N} \mathrm{HCl}$ (Nacalai Tesque, Inc.) was added to the plates. The absorbance of serum samples was measured at $450 \mathrm{~nm}$ with an iMark ${ }^{\mathrm{TM}}$ Microplate Absorbance Reader (Bio-Rad Laboratories, Inc., Hercules, CA, USA).

\subsection{T Cell Assay}

One week after the last immunization, single cell suspensions were prepared from the spleen of mice with a $100 \mu \mathrm{m}$ filter (Thermo Fisher Scientific, Inc.) and treated with $1 \mathrm{~mL}$ of red blood cell lysis buffer (1.5 M NH $4 \mathrm{Cl}$ (Nacalai Tesque, Inc.), $100 \mathrm{mM} \mathrm{KHCO}_{3}$ (Nacalai Tesque, Inc.), and $10 \mathrm{mM}$ EDTA-2Na (Nacalai Tesque, Inc.)) for $1 \mathrm{~min}$ at room temperature. Splenic CD4 ${ }^{+} \mathrm{T}$ cells were isolated with a magnetic cell separation system with CD4 (L3T4) microbeads (Miltenyi Biotec, Bergisch Gladbach, Germany) and MS Columns (Miltenyi Biotec), following the manufacturer's protocol. Antigen presenting cells (APCs) were prepared from the single cell suspensions and under 30 Gy of ionizing radiation by MBR-1520R-4 (Hitachi, Ltd., Tokyo, Japan). Splenic CD4 ${ }^{+}$T cells $\left(2 \times 10^{5}\right.$ cells/well) were seeded into Nunc ${ }^{\mathrm{TM}}$ 96-Well, Nunclon Delta-Treated, U-Shaped-Bottom Microplate (Thermo Fisher Scientific, Inc.) and incubated for 4 days with APCs $\left(1 \times 10^{4}\right.$ cells/well $)$ in $1 \mathrm{mg} / \mathrm{mL}$ OVA dissolved in complete RPMI-1640 medium (RPMI-1640 medium supplemented with 10\% fetal bovine serum (Life Technologies, Thermo Fisher Scientific, Inc., Waltham, MA, USA), 1\% $100 \mathrm{mM}$ sodium pyruvate solution (100×) (Nacalai Tesque, Inc.), 1\% penicillin-streptomycin mixed solution (Nacalai Tesque, Inc.), and 0.1\% 2-Mercaptoethanol (Gibco, Thermo Fisher Scientific, Inc., Waltham, MA, USA)). Cell viability was measured with CyQUANT ${ }^{\circledR}$ Cell Proliferation Assay Kits (Invitrogen, Thermo Fisher Scientific, Inc., Waltham, MA, USA). The absorbance of the cells was measured at 485/535 nm with an ARVO X2 (PerkinElmer, Yokohama, Japan) fluorescence microplate reader. The cell supernatants were collected and the cytokines interferon $\gamma$ (IFN- $\gamma$ ), IL-4, and IL-17 were detected with a BD ${ }^{\text {TM }}$ Cytometric Bead Array (CBA) Mouse Th1/Th2/Th17 Cytokine Kit (BD Biosciences, San Jose, CA, USA), following the manufacturer's protocol, and analyzed with a MACSQuant ${ }^{\circledR}$ Analyzer (Miltenyi Biotec).

\subsection{Preparation of Bone Marrow-Derived Dendritic Cells and Splenic Dendritic Cells}

Bone marrow-derived dendritic cells (BMDCs) were cultured as previously described [19]. Cells were harvested from the femoral bone marrow (BM) of female BALB/c mice aged 4-5 weeks. The BM cells were treated with red blood cell lysis buffer for $5 \mathrm{~min}$, and then, washed in complete RPMI-1640 medium. BMDCs were cultured in complete RPMI-1640 medium containing $20 \mathrm{ng} / \mathrm{mL}$ 
GM-CSF (PeproTech, Rocky Hill, NJ, USA). Half of the culture medium was replaced with fresh medium every 2 days. On day 6, BMDCs were purified using the MACS magnetic cell separation system with CD11c microbeads (Miltenyi Biotec) and LS Columns (Miltenyi Biotec), following the manufacturer's protocol. For analyzing splenic dendritic cells, single cell suspensions were prepared from the spleen of mice that were subcutaneously injected once after $4 \mathrm{~h}$ from the injection, with a $100 \mu \mathrm{m}$ filter (Thermo Fisher Scientific, Inc.) and treated with $1 \mathrm{~mL}$ of red blood cell lysis buffer (1.5 M NH $4 \mathrm{Cl}$ (Nacalai Tesque, Inc.), $100 \mathrm{mM} \mathrm{KHCO}_{3}$ (Nacalai Tesque, Inc.), and $10 \mathrm{mM}$ EDTA-2Na (Nacalai Tesque, Inc.)) for $1 \mathrm{~min}$ at room temperature.

\subsection{Measurement of Cytokines}

BMDCs $\left(1 \times 10^{5}\right.$ cells/well) or human peripheral blood mononuclear cells (PBMCs) $\left(2 \times 10^{5}\right.$ cells/well, FUJIFILM Wako Pure Chemical, Osaka, Japan) were seeded into a Nunc ${ }^{\text {TM }}$ 96-Well, Nunclon Delta-Treated, U-Shaped-Bottom Microplate (Thermo Fisher Scientific, Inc.) and incubated with various concentrations ( 0.1 or $1 \mathrm{ng} / \mathrm{mL}$ ) of Alcaligenes lipid A for 24 (PBMCs) or 48 (BMDCs) h at $37^{\circ} \mathrm{C}$. The cell culture supernatants were collected for the detection of cytokines via BD ${ }^{\mathrm{TM}} \mathrm{CBA}$ Mouse or Human Inflammation Kit (BD Biosciences), LEGEND MAX ${ }^{\mathrm{TM}}$ Human IL-1 $\beta$ ELISA Kit (BioLegend, San Diego, CA, USA), and LEGEND MAX'TM Mouse IL-23 (p19/p40) ELISA Kit (BioLegend).

\subsection{Flow Cytometry Analysis}

BMDCs or splenic cells were incubated for $15 \mathrm{~min}$ at room temperature with $5 \mu \mathrm{g} / \mathrm{mL}$ anti-CD16/32 antibody (Fc Block; clone: 93) (BioLegend), to avoid non-specific staining, and 7-AAD Viability Staining Solution (BioLegend), to detect dead cells. BMDCs or splenic cells were then stained for $30 \mathrm{~min}$ at $4{ }^{\circ} \mathrm{C}$ with following antibodies. For BMDCs, FITC-anti-I-A ${ }^{\mathrm{d}}$ (BioLegend; clone: 39-10-8), PE-anti-CD80 (BioLegend; clone: 16-10A1), APC-Cy7-anti-CD86 (BioLegend; clone: GL-1), and PE-Cy7-anti-CD40 (BioLegend; clone: 3/23) were used. For splenic cells, FITC-anti-I-A ${ }^{\mathrm{d}}$ (BioLegend; clone: 39-10-8), PE-anti-CD80 (BioLegend; clone: 16-10A1), and Brilliant Violet 421-anti-CD11c (BioLegend; clone: N418) were used. Samples were analyzed with a MACSQuant ${ }^{\circledR}$ Analyzer (Miltenyi Biotec). Flow cytometry data were analyzed with FlowJo, LLC Software 10.2 (BD Biosciences).

\subsection{Measurement of Blood Cells and Body Temperature in Mice}

Blood samples $(100 \mu \mathrm{L})$ were mixed with $1.5 \mu \mathrm{L}$ of $10 \mathrm{mM}$ EDTA-2Na (Nacalai Tesque, Inc.) and then, diluted 1:6 with saline solution (Otsuka Pharmaceutical Co., Ltd., Tokyo, Japan). The number of lymphocytes and platelets was measured with a Vet Scan HMII hematology analyzer (Abaxis, Union City, CA, USA). Body temperature was obtained by measuring the rectal temperature.

\subsection{Statistical Analyses}

The data are presented as mean \pm SD. Statistical analyses were performed using Student's $t$-test and one-way ANOVA with the Bonferroni post hoc test by PRISM (GraphPad Software, San Diego, CA, USA).

\section{Results}

\subsection{Enhancement of OVA-Specific Antibody Responses by Alcaligenes Lipid A}

To examine the effects of Alcaligenes lipid A on the induction of antigen-specific antibody responses, mice were subcutaneously injected with OVA alone or OVA plus Alcaligenes lipid A on days 1 and 10. One week after the last immunization, serum was collected to measure the levels of OVA-specific antibodies by enzyme-linked immunosorbent assay (ELISA). Levels of OVA-specific serum IgG were higher in mice immunized with $1 \mu \mathrm{g}$ of OVA plus Alcaligenes lipid A than in mice immunized with 1 or $10 \mu \mathrm{g}$ of OVA alone (Figure 1a). We further found that the OVA-specific IgG induced by immunization with $1 \mu \mathrm{g}$ of OVA plus Alcaligenes lipid A contained higher levels of OVA-specific serum IgG1, 
IgG2b, and IgG3 (Figure 1b). These results indicate that Alcaligenes lipid A enhances OVA-specific IgG responses.

\section{a}

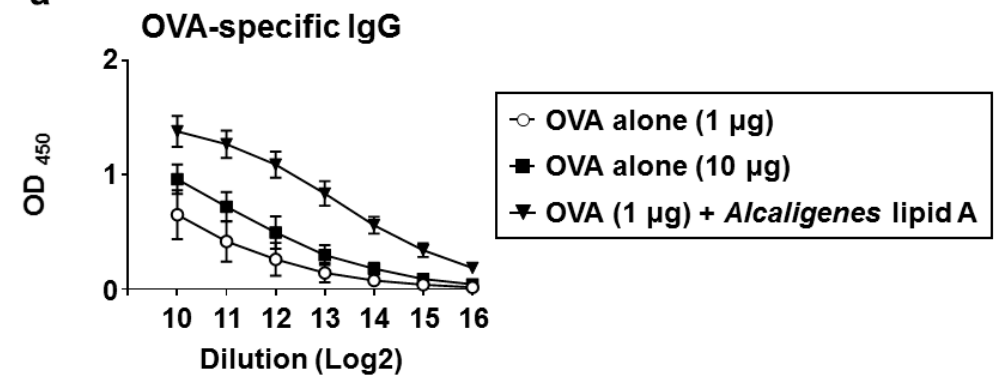

b
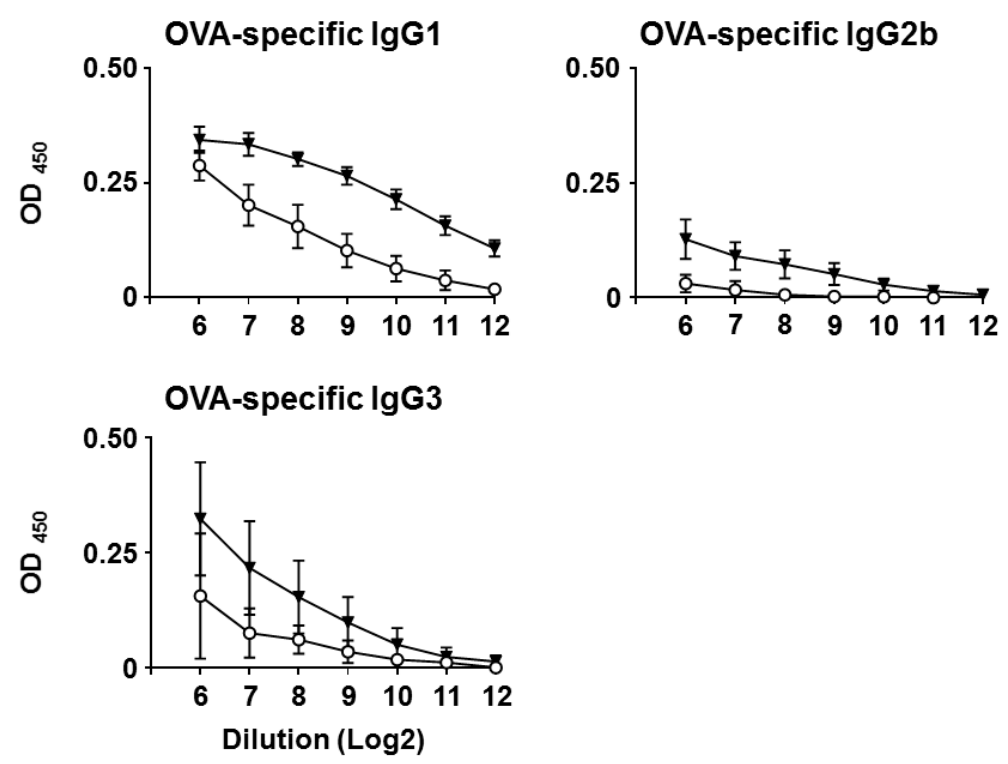

Figure 1. Enhancement of OVA-specific antibody responses by Alcaligenes lipid A. Mice were subcutaneously immunized with OVA plus Alcaligenes lipid A $(1 \mu \mathrm{g})$ or OVA alone (1 or $10 \mu \mathrm{g})$ on days 1 and 10. One week after the last immunization, serum was collected to measure with ELISA to determine the levels of OVA-specific IgG (a), IgG1, IgG2b, and IgG3 (b) ( $n=7$ per group). Data are a combination of two independent experiments.

\subsection{Enhancement of OVA-Specific T Cell Responses by Alcaligenes Lipid A}

We next examined the effects of Alcaligenes lipid A on OVA-specific T cell responses. To examine their proliferation and cytokine production, splenic $\mathrm{CD} 4^{+} \mathrm{T}$ cells were collected from mice immunized with OVA alone or OVA plus Alcaligenes lipid A. Splenic $\mathrm{CD} 4^{+} \mathrm{T}$ cells isolated from mice that had been immunized with OVA plus Alcaligenes lipid A proliferated significantly more upon antigen re-stimulation than did those isolated from mice that had been immunized with OVA alone (Figure 2a), indicating that Alcaligenes lipid A promoted the proliferation of OVA-specific $\mathrm{CD} 4^{+} \mathrm{T}$ cells.

Splenic $\mathrm{CD} 4^{+} \mathrm{T}$ cells from mice that had been immunized with OVA plus Alcaligenes lipid A also produced significantly higher levels of IL-17 compared with mice that had been immunized with OVA alone, but there were no differences in the production of IFN- $\gamma$ and IL-4 (Figure 2b). These results collectively indicate that Alcaligenes lipid A preferentially induces Th17 responses. 
a

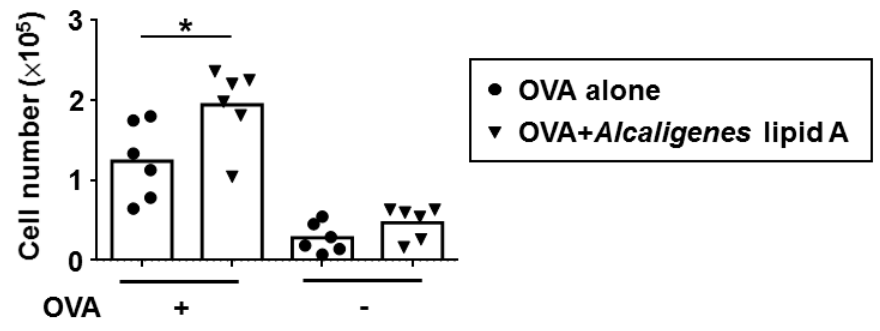

b
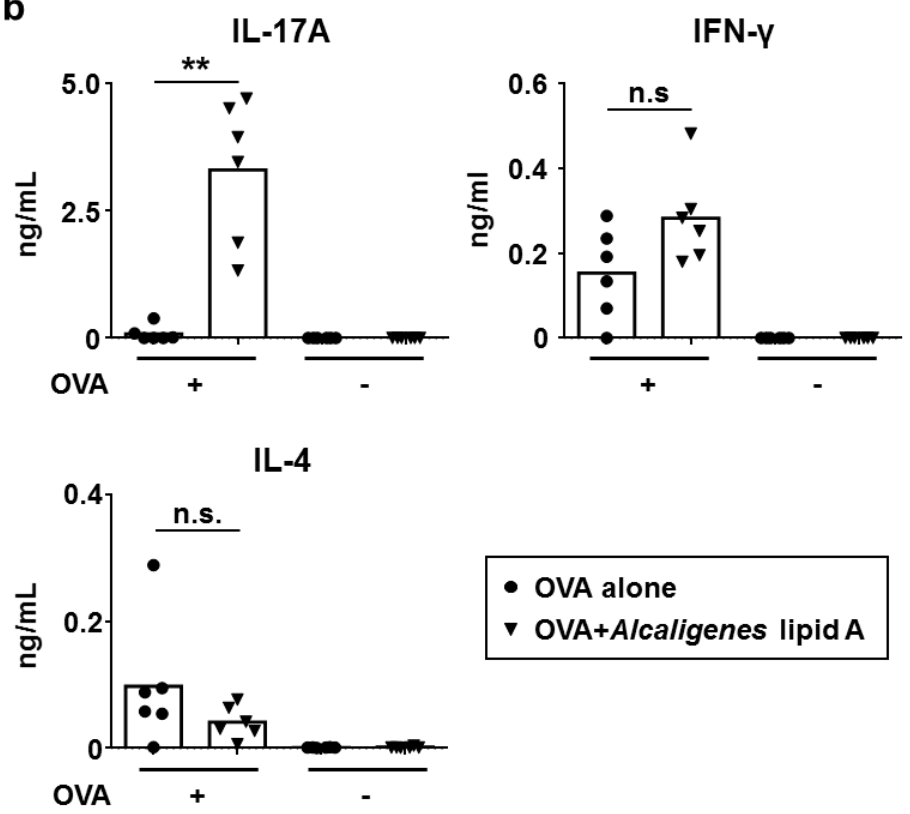

- OVA alone

$\checkmark$ OVA+Alcaligenes lipid A

Figure 2. Enhancement of OVA-specific T cell responses by Alcaligenes lipid A. Splenic CD4 ${ }^{+} \mathrm{T}$ cells were collected from mice subcutaneously immunized with OVA alone $(1 \mu \mathrm{g})$ or plus Alcaligenes lipid A $(1 \mu \mathrm{g})$. After ex vivo stimulation with OVA (+) or not (-), the number of T cells (a) and the production of IL-17, IFN- $\gamma$, and IL-4 in the culture supernatants (b) were measured ( $n=6$ per group). Data are a combination of two independent experiments and analyzed by Student's $t$-test ${ }^{*} p<0.05 ;{ }^{* *} p<0.01$; n.s.: not significant).

\subsection{Activation of Bone Marrow-Derived Dendritic Cells And Splenic Dendritic Cells by Alcaligenes Lipid A}

To examine the effects of Alcaligenes lipid A on the activation of DCs, we measured the expression level of MHC class II and costimulatory molecules (CD80 and CD86, related to activation of T cells; CD40, related to antibody production from B cells) on BMDCs. Stimulation with Alcaligenes lipid A significantly increased the expression level of MHC class II, CD80, CD86, and CD40 on BDMCs in a dose-dependent manner (Figure 3a). Furthermore, consistent with the preferential induction of Th17 cells, Alcaligenes lipid A activated BMDCs to produce IL-6 and IL-23, which are cytokines involved in Th17 cell differentiation and subsequent stabilization (Figure $3 \mathrm{~b}$ ). In addition, we also analyzed the expression level of MHC class II and costimulatory molecules CD80 in vivo. Mice subcutaneously injected with OVA and Alcaligenes lipid A significantly increased the numbers of the $\mathrm{CD} 11 \mathrm{c}^{+} \mathrm{MHC}$ class $\mathrm{II}^{+} \mathrm{CD} 80^{+} \mathrm{DC}$ in spleen (Figure S1). These findings collectively indicate that Alcaligenes lipid A activates DCs and creates an environment that is preferential for the induction of Th17 cells. 
a
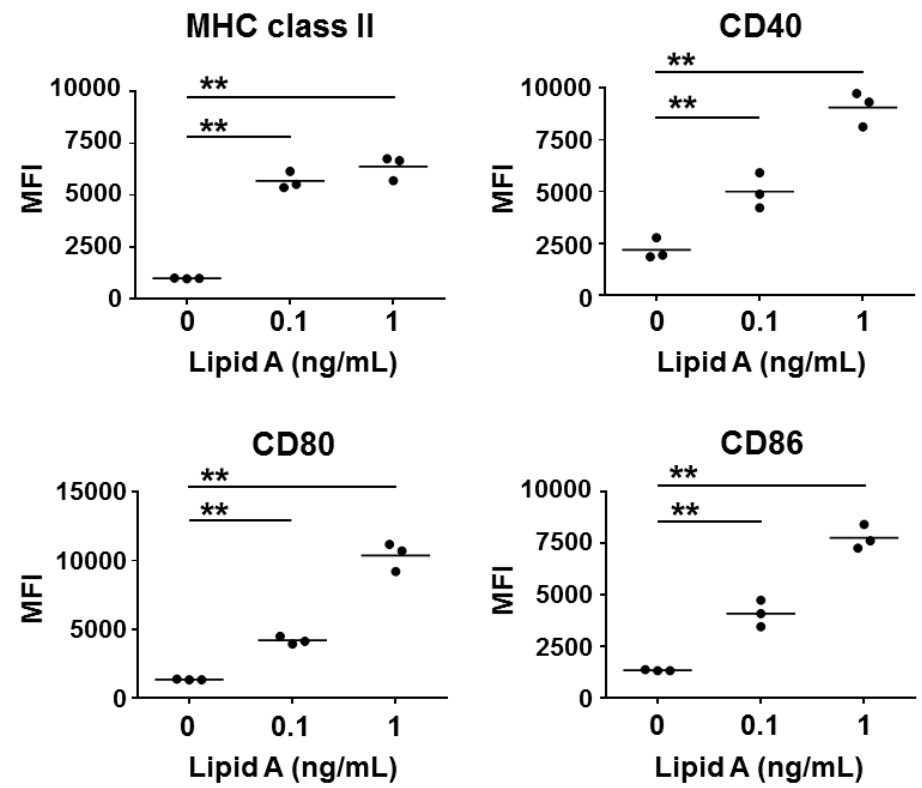

b
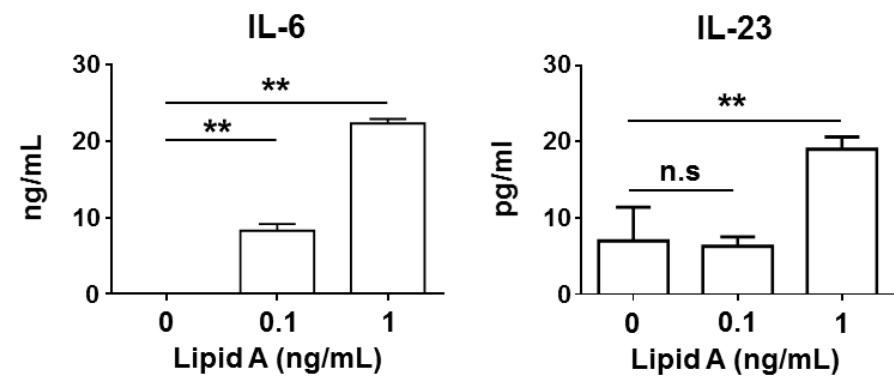

Figure 3. Activation of BMDCs by Alcaligenes lipid A. Murine BMDCs were stimulated with 0 (control), 0.1 or $1 \mathrm{ng} / \mathrm{mL}$ Alcaligenes lipid A. After incubation for $48 \mathrm{~h}$, the expression of MHC class II, CD80, CD86, and CD40 (a) and the production of IL-6 and IL-23 in the culture supernatant (b) were analyzed ( $n=3$ per group). Data are representative of two independent experiments and analyzed by one-way ANOVA (** $p<0.01$; n.s.: not significant).

\subsection{Activation of Human Immune Cells by Alcaligenes Lipid A}

To consider the effects of Alcaligenes lipid A on human immune cells, we measured the production of cytokines from human PBMCs from two individuals; both showed increased levels of IL-6 and IL-1 $\beta$, which are required for the initiation and stabilization of human Th17 cells (Figure S2). These results indicate that Alcaligenes lipid A activate human immune cells, especially those that contribute toward the induction of Th17 cells.

\subsection{Safety of Alcaligenes Lipid A}

To investigate the safety of Alcaligenes lipid A, we examined the numbers of lymphocytes and platelets in the blood of mice $24 \mathrm{~h}$ after immunization. The numbers of lymphocytes and platelets from mice after immunization with OVA plus Alcaligenes lipid A were reduced compared with those from mice that were immunized with OVA alone; however, the levels remained within the normal physiological ranges of mice (Figure $4 \mathrm{a}$ ). 
a
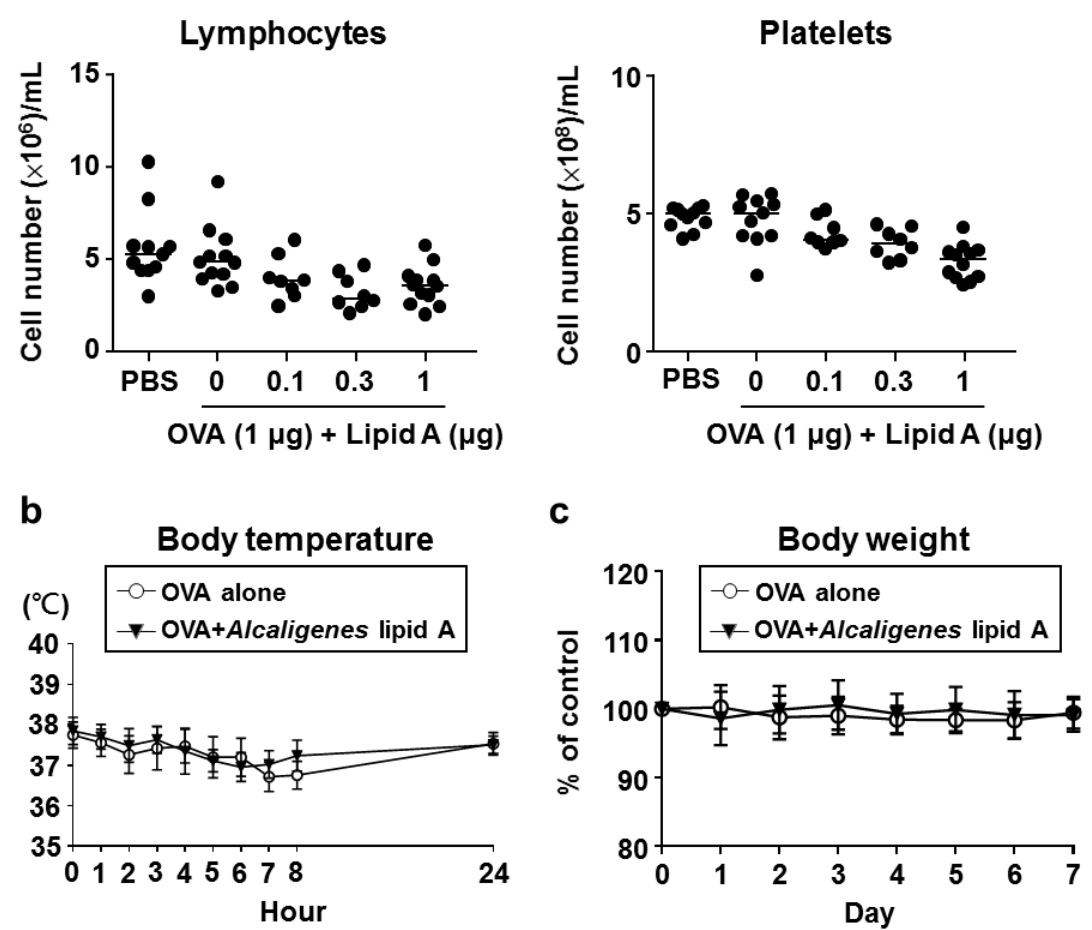

Figure 4. Safety of Alcaligenes lipid A. Mice were immunized with OVA or OVA plus Alcaligenes lipid A. The numbers of lymphocytes and platelets in the blood were measured $24 \mathrm{~h}$ after immunization (a). Body temperature (b) was monitored at $0,1,8$, and $24 \mathrm{~h}$; and body weight (c) for 7 days after immunization ( $n=8-12$ per group). Data are a combination of three independent experiments.

We further surveyed body temperature at $0,1,8$, and $24 \mathrm{~h}$ after immunization. Immunization with OVA and Alcaligenes lipid A or OVA alone led to no significant changes in body temperature (Figure 4b). Similarly, for both groups, body weight did not significantly change after immunization (Figure 4c). Collectively, these results indicate that immunization with Alcaligenes lipid A did not cause severe side effects in mice.

\section{Discussion}

In this study, we have demonstrated the efficacy and safety of Alcaligenes lipid A when used as an adjuvant in systemic vaccination. Lipid A is a core component of LPS, and its activity related to TLR4 agonist or antagonist is determined by its structure, including the number of acyl chains and phosphate groups, and the length of acyl chains [23,24]. For use as a vaccine adjuvant, the balance of the structure-activity relationship between efficacy and safety is the issue that has to be considered. For example, 3-O-desacyl-4'-monophosphoryl lipid A (MPL) is generated by modification of the dephosphorylating of one phosphate group of the lipid A of Salmonella minnesota to reduce its toxicity [25-30]. Similarly, the monophosphoryl lipid A from Bordetella pertussis and Escherichia coli has also been reported as an effective adjuvant [31-35]. Alcaligenes lipid A has the same structure as E. coli, with six acyl chains and two phosphate groups. However, the length of the acyl chains in the structure of Alcaligenes lipid A is shorter than that of E. coli [22], suggesting that the structural uniqueness of Alcaligenes lipid A provides effectiveness and safety when used as a vaccine adjuvant. Previous works on lipid A as a vaccine adjuvant focus on lipid A from S. minnesota, B. pertussis, and E. coli, which are pathogenic bacteria. Our studies showed that when lipid A from Alcaligenes, a symbiotic bacterium that resides inside the PPs of various mammalian species, is used as vaccine adjuvant in mice experiments, it is effective and safe without modifying its structure [22]. 
One of the unique properties of Alcaligenes lipid A is the induction of antigen-specific Th17 responses. In contrast, MPL from S. minnesota and monophosphoryl lipid A from B. pertussis and E. coli promote IFN- $\gamma$-producing Th1 responses in mice [30,31,34]. Th17 cells are important in conferring protection against extracellular bacterial and fungal infections; therefore, Alcaligenes lipid A could be useful as an adjuvant in vaccines against these types of infections.

To understand the mechanism underlying the preferential induction of Th17 responses, the effects of Alcaligenes lipid A on DCs were examined. DCs present antigen to T cells via MHC class II and costimulatory molecules, such as CD80 and CD86 [36,37], expression of which are upregulated by Alcaligenes lipid A. Moreover, the cytokine pattern produced by DCs determine the direction of $\mathrm{T}$ helper cell differentiation. For example, IFN- $\gamma$ and IL-12 induce the differentiation of Th1 cells, whereas IL-4 induces the differentiation of Th2 cells. Transforming growth factor beta (TGF- $\beta$ ) and IL-6 promote the differentiation of Th17 cells, and IL-23 promotes the stabilization of Th17 cells in mice [38-40]. Consistent with our previous reports about Alcaligenes-mediated activation of DCs [11,12,19], Alcaligenes lipid A increased IL-6 and IL-23 production from murine BMDCs. Furthermore, human PBMCs that were stimulated by Alcaligenes lipid A had increased production of IL-6 and IL-1 $\beta$, which contribute to the differentiation and stabilization of human Th17 cells [38-41]. IL-23 was also produced by the PBMCs; however, unlike IL- 6 and IL-1 $\beta$, the reactivity was different among the individuals. This difference between individuals indicates that Alcaligenes lipid A may have multiple pathways to induce human Th17 development [38-41].

In addition, Alcaligenes lipid A enhanced the expression of CD40 on BMDCs, suggesting that Alcaligenes lipid A could induce antibody production via the $\mathrm{T}$ cell independent pathway. CD40 expressed on DCs plays a role in regulating B cell proliferation by the direct interaction via CD40L expressed on B cells, leading to enhance IgG production [42]. Consistently, we found that Alcaligenes lipid A induced the production of antigen-specific IgG1, IgG2b, and IgG3 in the serum. Similarly, it was reported that MPL of $S$. minnesota enhances the production of $\operatorname{IgG} 2 \mathrm{a}$ and $\operatorname{IgG} 2 \mathrm{~b}[26,28]$, and monophosphoryl lipid A of B. pertussis and E. coli both enhance the production of IgG2a [31,35]. In addition, MPL of $S$. minnesota and monophosphoryl lipid A of B. pertussis and E. coli slightly increase IgG1 production $[26,28,31,35]$. The results of the current study are consistent with previous works that demonstrated that Th1 cells produce IFN- $\gamma$ to induce IgG2a and IgG2b, while Th2 cells produce IL-4 to induce IgG1 [43,44]. Th17 cells induce IgG1, IgG2b, and IgG3 via the secretion of IL-17A or IL-21 [45]. IgG1 and IgG3 contribute toward the activation of phagocytosis by macrophages and neutrophils and activation of complement, both of which help to defend against bacterial infections [46]. These findings indicate that Alcaligenes lipid A could be an effective adjuvant in vaccines against extracellular bacterial infections.

Adjuvant safety is another important factor for clinical use. For example, complete Freund's adjuvant is a well-known strong adjuvant that is widely used in animal experiments; however, it cannot be used clinically because of side effects, such as severe inflammation. In this regard, Alcaligenes lipid A did not cause severe side effects, which is consistent with our previous studies on Alcaligenes LPS. Injection with $1 \mu \mathrm{g}$ of Alcaligenes lipid A showed efficacy and without severe side effects such as lymphopenia and thrombocytopenia in mice. However, we noticed that injection with more than $1 \mu \mathrm{g}$ of Alcaligenes lipid A caused lymphopenia and thrombocytopenia in mice; therefore, when considering clinical use, it is necessary to reduce the side effects of Alcaligenes lipid A by setting a safe dose or modifying the structure.

\section{Conclusions}

We have demonstrated the efficacy and safety of chemically synthesized Alcaligenes lipid A when used as an adjuvant in systemic vaccination. Alcaligenes lipid A promoted both antigen-specific IgG antibody and Th17 responses in mice by directly stimulating DCs. Stimulation with Alcaligenes lipid A also induced the production of IL-6 and IL-1 $\beta$ in human PBMCs, suggesting a potency to be applied for use in human. 
Supplementary Materials: The following are available online at http://www.mdpi.com/2076-393X/8/3/395/s1, Figure S1: Activation of splenic CD11c+ DCs by Alcaligenes lipid A. Mice were subcutaneously injected once with OVA plus Alcaligenes lipid A $(1 \mu \mathrm{g})$ or OVA alone $(1 \mu \mathrm{g}) .4$ hours after the injection, spleen was collected to analyze the expression of MHC class II and CD80 on CD11c+ DCs with flow cytometry ( $n=4$ per group). Data analyzed by Student's t-test $(* * p<0.01)$, Figure S2: PBMC activation by Alcaligenes lipid A. Human PBMCs from two individuals were stimulated with 0 (control) or $1 \mathrm{ng} / \mathrm{mL}$ Alcaligenes lipid A. After a 24-h incubation, cytokines in the supernatant were measured ( $n=2$ per group).

Author Contributions: Conceptualization, J.K.; methodology, K.H. and T.N. (Takahiro Nagatake); formal analysis, Y.W. and K.H.; investigation, Y.W., K.H., K.Y. and T.N. (Tomomi Nishino); resources, A.S., H.Y. and K.F.; data curation, Y.W. and K.H.; writing - original draft preparation, Y.W., K.H. and J.K; writing-review and editing, Y.W., K.H., A.S., T.N. (Takahiro Nagatake), H.K., K.F. and J.K.; visualization, Y.W. and K.H.; supervision, K.F. and J.K.; funding acquisition, K.H., A.S., K.F. and J.K. All authors have read and agreed to the published version of the manuscript.

Funding: This research was supported by the Ministry of Education, Culture, Sports, Science, and Technology of Japan and the Japan Society for the Promotion of Science under grant numbers JP18H02150 (J.K.), JP18H02674 (J.K.), JP17K09604 (J.K.) JP18K17997 (K.H.), JP15H05836 (K.F.), JP16K01914 (A.S.), JP19KK0145 (K.F.), JP20H04776 (A.S.), JP20K05749 (A.S.); the Japan Agency for Medical Research and Development (AMED) under grant numbers JP17fk0108223h0002 (J.K.), JP17ek0410032s0102 (J.K.), JP17fk0108207h0002 (J.K.), JP17ek0210078h0002 (J.K.), JP17ak0101068h0001 (J.K.), JP17gm1010006s0101 (J.K.), JP18ck0106243h0003 (J.K.) and JP19ek0410062h0001 (J.K.); the Ministry of Health, Labour, and Welfare of Japan under grant number JP19KA3001 (J.K. and K.H.); the Terumo Foundation for Life Sciences and Arts (J.K.); the ONO Medical Research Foundation (J.K.); the Canon Foundation (J.K.); and Cross-ministerial Strategic Innovation Promotion Program (SIP; to J.K.); the Joint Research Project of the Institute of Medical Science, the University of Tokyo (J.K.) and Public/Private R\&D Investment Strategic Expansion PrograM (PRISM; to J.K.).

Acknowledgments: The authors would like to thank the members of the Laboratory of Vaccine Materials, Center for Vaccine and Adjuvant Research, and Laboratory of Gut Environmental System, National Institutes of Biomedical Innovation, Health and Nutrition (NIBIOHN) for their advice, encouragement, and their help.

Conflicts of Interest: The authors declare no conflict of interest. The funders did not participate in the design of the study; in the collection, analyses, or interpretation of data; in the writing of the manuscript, or in the decision to publish the results.

\section{References}

1. Thaiss, C.A.; Zmora, N.; Levy, M.; Elinav, E. The microbiome and innate immunity. Nature 2016, 535, 65-74. [CrossRef]

2. Honda, K.; Littman, D.R. The microbiota in adaptive immune homeostasis and disease. Nature 2016, 535, 75-84. [CrossRef]

3. Brown, E.M.; Kenny, D.J.; Xavier, R.J. Gut Microbiota Regulation of T Cells During Inflammation and Autoimmunity. Annu. Rev. Immunol. 2019, 37, 599-624. [CrossRef]

4. Dollé, L.; Tran, H.Q.; Etienne-Mesmin, L.; Chassaing, B. Policing of gut microbiota by the adaptive immune system. BMC Med. 2016, 14, 27. [CrossRef]

5. Zhang, Z.; Li, J.; Zheng, W.; Zhao, G.; Zhang, H.; Wang, X.; Guo, Y.; Qin, C.; Shi, Y. Peripheral Lymphoid Volume Expansion and Maintenance Are Controlled by Gut Microbiota via RALDH+ Dendritic Cells. Immunity 2016, 44, 330-342. [CrossRef]

6. Pollard, M.; Sharon, N. Responses of the Peyer's Patches in Germ-Free Mice to Antigenic Stimulation. Infect. Immun. 1970, 2, 96-100. [CrossRef]

7. Kennedy, E.A.; King, K.Y.; Baldridge, M.T. Mouse microbiota models: Comparing germ-free mice and antibiotics treatment as tools for modifying gut bacteria. Front. Physiol. 2018, 9, 1534. [CrossRef]

8. Bouskra, D.; Brézillon, C.; Bérard, M.; Werts, C.; Varona, R.; Boneca, I.G.; Eberl, G. Lymphoid tissue genesis induced by commensals through NOD1 regulates intestinal homeostasis. Nature 2008, 456, 507-510. [CrossRef]

9. Ivanov, I.I.; Atarashi, K.; Manel, N.; Brodie, E.L.; Shima, T.; Karaoz, U.; Wei, D.; Goldfarb, K.C.; Santee, C.A.; Lynch, S.V.; et al. Induction of Intestinal Th17 Cells by Segmented Filamentous Bacteria. Cell 2009, 139, 485-498. [CrossRef]

10. Atarashi, K.; Tanoue, T.; Shima, T.; Imaoka, A.; Kuwahara, T.; Momose, Y.; Cheng, G.; Yamasaki, S.; Saito, T.; Ohba, Y.; et al. Induction of Colonic Regulatory T Cells by Indigenous Clostridium Species. Science 2011, 331, 337-341. [CrossRef] 
11. Obata, T.; Goto, Y.; Kunisawa, J.; Sato, S.; Sakamoto, M.; Setoyama, H.; Matsuki, T.; Nonaka, K.; Shibata, N.; Gohda, M.; et al. Indigenous opportunistic bacteria inhabit mammalian gut-associated lymphoid tissues and share a mucosal antibody-mediated symbiosis. Proc. Natl. Acad. Sci. USA 2010, 107, 7419-7424. [CrossRef]

12. Kunisawa, J.; Kiyono, H. Alcaligenes is Commensal Bacteria Habituating in the Gut-Associated Lymphoid Tissue for the Regulation of Intestinal IgA Responses. Front. Immunol. 2012, 3. [CrossRef] [PubMed]

13. Ramakrishna, C.; Kujawski, M.; Chu, H.; Li, L.; Mazmanian, S.K.; Cantin, E.M. Bacteroides fragilis polysaccharide A induces IL-10 secreting B and T cells that prevent viral encephalitis. Nat. Commun. 2019, 10, 2153. [CrossRef] [PubMed]

14. Vatanen, T.; Kostic, A.D.; D’Hennezel, E.; Siljander, H.; Franzosa, E.A.; Yassour, M.; Kolde, R.; Vlamakis, H.; Arthur, T.D.; Hämäläinen, A.-M.; et al. Variation in Microbiome LPS Immunogenicity Contributes to Autoimmunity in Humans. Cell 2016, 165, 842-853. [CrossRef] [PubMed]

15. Reed, S.G.; Hsu, F.-C.; Carter, D.; Orr, M.T. The science of vaccine adjuvants: Advances in TLR4 ligand adjuvants. Curr. Opin. Immunol. 2016, 41, 85-90. [CrossRef] [PubMed]

16. Sun, B.; Yu, S.; Zhao, D.; Guo, S.; Wang, X.; Zhao, K. Polysaccharides as vaccine adjuvants. Vaccine 2018, 36, 5226-5234. [CrossRef]

17. Weinberger, B. Adjuvant strategies to improve vaccination of the elderly population. Curr. Opin. Pharmacol. 2018, 41, 34-41. [CrossRef]

18. Dowling, D.; van Haren, S.; Scheid, A.; Bergelson, I.; Kim, D.; Mancuso, C.; Foppen, W.; Ozonoff, A.; Fresh, L.; Theriot, T.; et al. TLR7/8 adjuvant overcomes newborn hyporesponsiveness to pneumococcal conjugate vaccine at birth. JCI Insight 2017, 2, e91020. [CrossRef]

19. Shibata, N.; Kunisawa, J.; Hosomi, K.; Fujimoto, Y.; Mizote, K.; Kitayama, N.; Shimoyama, A.; Mimuro, H.; Sato, S.; Kishishita, N.; et al. Lymphoid tissue-resident Alcaligenes LPS induces IgA production without excessive inflammatory responses via weak TLR4 agonist activity. Mucosal Immunol. 2018, 11, 693-702. [CrossRef] [PubMed]

20. Steimle, A.; Autenrieth, I.B.; Frick, J.-S. Structure and function: Lipid A modifications in commensals and pathogens. Int. J. Med. Microbiol. 2016, 306, 290-301. [CrossRef] [PubMed]

21. Fujimoto, Y.; Shimoyama, A.; Saeki, A.; Kitayama, N.; Kasamatsu, C.; Tsutsui, H.; Fukase, K. Innate immunomodulation by lipophilic termini of lipopolysaccharide; synthesis of lipid As from Porphyromonas gingivalis and other bacteria and their immunomodulative responses. Mol. Biosyst. 2013, 9, 987-996. [CrossRef] [PubMed]

22. Kunisawa, J.; Fukase, K.; Kiyono, H. Lipid A Containing Complex of Glucosamine Disaccharide Chain and Fatty Acid Chains and Adjuvant Using It. WIPO (PCT) WO2018155051A1, 30 August 2018. Available online: https://patents.google.com/patent/WO2018155051A1/en (accessed on 17 July 2020).

23. Cochet, F.; Peri, F. The Role of Carbohydrates in the Lipopolysaccharide (LPS)/Toll-Like Receptor 4 (TLR4) Signalling. Int. J. Mol. Sci. 2017, 18, 2318. [CrossRef] [PubMed]

24. Park, B.S.; Song, D.H.; Kim, H.M.; Choi, B.-S.; Lee, H.; Lee, J.-O. The structural basis of lipopolysaccharide recognition by the TLR4-MD-2 complex. Nature 2009, 458, 1191-1195. [CrossRef] [PubMed]

25. Ribi, E.; Parker, R.; Strain, S.M.; Mizuno, Y.; Nowotny, A.; VonEschen, K.B.; Cantrell, J.L.; McLaughlin, C.A.; Hwang, K.M.; Goren, M.B. Peptides as requirement for immunotherapy of the guinea-pig line-10 tumor with endotoxins. Cancer Immunol. Immunother. 1979, 7, 43-58. [CrossRef]

26. Baldridge, J. Monophosphoryl lipid A enhances mucosal and systemic immunity to vaccine antigens following intranasal administration. Vaccine 2000, 18, 2416-2425. [CrossRef]

27. Mata-Haro, V.; Cekic, C.; Martin, M.; Chilton, P.M.; Casella, C.R.; Mitchell, T.C. The Vaccine Adjuvant Monophosphoryl Lipid A as a TRIF-Biased Agonist of TLR4. Science 2007, 316, 1628-1632. [CrossRef]

28. Chilton, P.M.; Hadel, D.M.; To, T.T.; Mitchell, T.C.; Darveau, R.P. Adjuvant Activity of Naturally Occurring Monophosphoryl Lipopolysaccharide Preparations from Mucosa-Associated Bacteria. Infect. Immun. 2013, 81, 3317-3325. [CrossRef]

29. Apostólico, J.; Lunardelli, V.; Coirada, F.; Boscardin, S.; Rosa, D. Adjuvants: Classification, Modus Operandi, and Licensing. J. Immunol. Res. 2016, 2016, 1459394. [CrossRef]

30. Genito, C.J.; Beck, Z.; Phares, T.W.; Kalle, F.; Limbach, K.J.; Stefaniak, M.E.; Patterson, N.B.; Bergmann-Leitner, E.S.; Waters, N.C.; Matyas, G.R.; et al. Liposomes containing monophosphoryl lipid A and QS-21 serve as an effective adjuvant for soluble circumsporozoite protein malaria vaccine FMP013. Vaccine 2017, 35, 3865-3874. [CrossRef] 
31. Quintilio, W.; Kubrusly, F.S.; Iourtov, D.; Miyaki, C.; Sakauchi, M.A.; Lúcio, F.; deCássia Dias, S.; Takata, C.S.; Miyaji, E.N.; Higashi, H.G.; et al. Bordetella pertussis monophosphoryl lipid A as adjuvant for inactivated split virion influenza vaccine in mice. Vaccine 2009, 27, 4219-4224. [CrossRef]

32. Quintilio, W.; de Freitas, F.A.; Rodriguez, D.; Kubrusly, F.S.; Yourtov, D.; Miyaki, C.; de Cerqueira Leite, L.C.; Raw, I. Vitamins as influenza vaccine adjuvant components. Arch. Virol. 2016, 161, 2787-2795. [CrossRef]

33. Fernandes, L.G.V.; Teixeira, A.F.; Filho, A.F.S.; Souza, G.O.; Vasconcellos, S.A.; Heinemann, M.B.; Romero, E.C.; Nascimento, A.L.T.O. Immune response and protective profile elicited by a multi-epitope chimeric protein derived from Leptospira interrogans. Int. J. Infect. Dis. 2017, 57, 61-69. [CrossRef] [PubMed]

34. Jeong, Y.; Kim, G.B.; Ji, Y.; Kwak, G.-J.; Nam, G.-H.; Hong, Y.; Kim, S.; An, J.; Kim, S.H.; Yang, Y.; et al. Dendritic cell activation by an E. coli-derived monophosphoryl lipid A enhances the efficacy of PD-1 blockade. Cancer Lett. 2020, 472, 19-28. [CrossRef]

35. Ji, Y.; An, J.; Hwang, D.; Ha, D.H.; Lim, S.M.; Lee, C.; Zhao, J.; Song, H.K.; Yang, E.G.; Zhou, P.; et al. Metabolic engineering of Escherichia coli to produce a monophosphoryl lipid A adjuvant. Metab. Eng. 2020, 57, 193-202. [CrossRef]

36. Zhao, Y.; Hanniffy, S.; Arce-Gorvel, V.; Conde-Alvarez, R.; Oh, S.; Moriyón, I.; Mémet, S.; Gorvel, J.-P. Immunomodulatory properties of Brucella melitensis lipopolysaccharide determinants on mouse dendritic cells in vitro and in vivo. Virulence 2018, 9, 465-479. [CrossRef]

37. Audiger, C.; Rahman, M.J.; Yun, T.J.; Tarbell, K.V.; Lesage, S. The Importance of Dendritic Cells in Maintaining Immune Tolerance. J. Immunol. 2017, 198, 2223-2231. [CrossRef]

38. Korn, T.; Bettelli, E.; Oukka, M.; Kuchroo, V.K. IL-17 and Th17 Cells. Annu. Rev. Immunol. 2009, $27,485-517$. [CrossRef]

39. Patel, D.D.; Kuchroo, V.K. Th17 Cell Pathway in Human Immunity: Lessons from Genetics and Therapeutic Interventions. Immunity 2015, 43, 1040-1051. [CrossRef]

40. Knochelmann, H.M.; Dwyer, C.J.; Bailey, S.R.; Amaya, S.M.; Elston, D.M.; Mazza-McCrann, J.M.; Paulos, C.M. When worlds collide: Th17 and Treg cells in cancer and autoimmunity. Cell. Mol. Immunol. 2018, 15, 458-469. [CrossRef]

41. Revu, S.; Wu, J.; Henkel, M.; Rittenhouse, N.; Menk, A.; Delgoffe, G.M.; Poholek, A.C.; McGeachy, M.J. IL-23 and IL-1 $\beta$ Drive Human Th17 Cell Differentiation and Metabolic Reprogramming in Absence of CD28 Costimulation. Cell Rep. 2018, 22, 2642-2653. [CrossRef]

42. Ma, D.; Clark, E. The role of CD40 and CD154/CD40L in dendritic cells. Semin. Immunol. 2009, 21, $265-272$. [CrossRef] [PubMed]

43. Gracie, J.A.; Bradley, J.A. Interleukin-12 induces interferon- $\gamma$-dependent switching of IgG alloantibody subclass. Eur. J. Immunol. 1996, 26, 1217-1221. [CrossRef]

44. Mosmann, T.R.; Coffman, R.L. TH1 and TH2 Cells: Different Patterns of Lymphokine Secretion Lead to Different Functional Properties. Annu. Rev. Immunol. 1989, 7, 145-173. [CrossRef]

45. Mitsdoerffer, M.; Lee, Y.; Jager, A.; Kim, H.-J.; Korn, T.; Kolls, J.K.; Cantor, H.; Bettelli, E.; Kuchroo, V.K. Proinflammatory T helper type 17 cells are effective B-cell helpers. Proc. Natl. Acad. Sci. USA 2010, 107, 14292-14297. [CrossRef] [PubMed]

46. Scott-Taylor, T.H.; Axinia, S.; Amin, S.; Pettengell, R. Immunoglobulin G; structure and functional implications of different subclass modifications in initiation and resolution of allergy. Immun. Inflamm. Dis. 2018, 6, 13-33. [CrossRef] [PubMed]

(C) 2020 by the authors. Licensee MDPI, Basel, Switzerland. This article is an open access article distributed under the terms and conditions of the Creative Commons Attribution (CC BY) license (http://creativecommons.org/licenses/by/4.0/). 